\title{
Traduzindo neologismos ideológicos
}

\author{
Luis Henrique Labres'
}

Se a rosa tivesse outro nome, ainda assim teria o mesmo perfume.

William Shakespeare

\begin{abstract}
Resumo: O artigo mostra um estudo sobre o dialeto dread talk. (DT), falado principalmente na Jamaica e em outras ilhas caribenhas. Trata-se de um dialeto cuja maior especificidade é a readequação de palavras de acordo com seu significado (ex.: o neologismo downpression em vez de oppression); seus falantes pertencem a um movimento chamado rastafári. A análise do dialeto foca nos aspectos socioculturais, ideológicos e motivacionais. Buscaram-se usos do DT em livros, sites específicos e em diversos corpora. Analisou-se a história social, cultural e linguística da Jamaica e do rastafári. Procedeu-se ao estudo do DT, apontando as possiveis dificuldades de tradução. Esses foram classificados de modo a estabelecer critérios de tradução para o português. Por fim, o artigo apresenta o caminho para o prosseguimento do estudo.
\end{abstract}

Palavras-chave: tradução sociocultural; dread talk; Jamaica.

\section{Introdução}

O dread talk (DT) é um dialeto utilizado para a comunicação entre os falantes de um grupo social específico, sendo que sua criação tem motivações diversas. Será necessário traçar algumas linhas para contextualizar essas motivações, explicando a cultura local da época em que surge (década de 60). O DT emergiu no Caribe, em Kingston, na Jamaica, como veremos, e o grupo social que utiliza esse dialeto

1 Tradutor autônomo especialista em Estudos da Tradução pela PUCRS. 
é chamado de rastafári. Tem por base o inglês, mas é modificado consciente e arbitrariamente, influenciado por uma ideologia bastante crítica dos modelos da época. Uma de suas características é a não submissão à imposição linguística inglesa, mobilizando adeptos a estudar intensamente o idioma, mas com olhar crítico, para que proponham readequações em palavras que, segundo os idealizadores, não condizem com seu conceito. É nessa característica linguística que o trabalho está focado, iniciando no item 1 pelo histórico geral da ilha, integrando o surgimento do movimento rastafári e as condições de criação do dialeto. Em seguida, a estrutura do dialeto é explicitada. O item 2 apresenta a correlação teórica, sustentada pela sociolinguística e pelos estudos da tradução. No item 3 dá-se a conclusão do artigo, revelando a importância de tais considerações e os possíveis rumos dessa linha teórica.

\section{Diáspora após diáspora}

O DT originou-se na Jamaica, originalmente chamada de Xaymaca por seus primeiros habitantes - os índios arawaks (MULVANEY, 1990). Apesar de ser uma ilha relativamente pequena, ela abunda tanto em diversidade natural quanto cultural devido a uma história social bastante movimentada. Colombo encontrou a ilha em 1494. A Espanha, que ali se estabeleceu em 1509, escravizou o povo indígena e trouxe da África dezenas de milhares de africanos com o mesmo fim. Após cem anos, quase nenhum arawak sobrevivera, senão aqueles que se refugiaram nas montanhas. Porém, pode-se perceber sua presença em nomes de objetos ou eventos naturais que perduraram, como savannah, hurricane e cassava.

Em 1655, os ingleses invadiram a ilha e expulsaram quase todos os espanhóis, exceto aqueles que se refugiaram em quilombos (ou comunidades maroon) com os poucos índios sobreviventes. Com a colonização inglesa, vieram como escravos, dessa vez, centenas de milhares de africanos de tribos distintas. Muitos deles fugiram para os mesmos quilombos onde se encontravam índios, africanos ocidentais, espanhóis e seus rebentos mestiços. Esses novos quilombolas falavam um pidgin baseado no inglês, que aprenderam para se comunicar com seus donos, além de suas diferentes línguas africanas (Lalla e D'costa, 1990).

Vivendo tão próximos uns dos outros, não puderam evitar que suas línguas se misturassem, afinal, de alguma forma os grupos precisavam se comunicar. Labov (2010) se refere a esse fenômeno quando trata dos aspectos geográficos relacionados à convergência ou divergência linguística e comenta ser natural duas línguas divergirem quando se afastam geograficamente e convergirem quando 
se aproximam. A aproximação desses diversos grupos foi um fator essencial na construção do dialeto que viria a se formar. Outras línguas vieram se somar a essa mistura inicial de espanhol, línguas africanas, língua arawak e pidgin do inglês. Lalla e D'costa (1990) ainda citam migrações menos expressivas de portugueses, índios miskito e povos de outras ilhas caribenhas. Esses povos não tinham direitos, condições de buscar melhoria de vida, sequer uma identidade, já que a maioria fora enxertada num lugar desconhecido. Grande parte deles ainda buscava uma identidade no começo do século XX.

Chevannes (1994) aponta que desde os anos 1880 os habitantes da ilha já emigravam na tentativa de fugir da pobreza. Em 1921, iniciou-se um movimento migratório interno, buscando fugir do empobrecimento rural, pela falta de terras adequadas. Dessa vez, o destino era a capital, Kingston. De 1921 a 1943 a população da cidade mais que dobrou, chegando a quase meio milhão de pessoas em 1960.

É nessa época, com Kingston superpovoada nos subúrbios, com habitantes expostos a doenças, parasitismo e roubos, que surge o movimento rastafári. Segundo Chevannes (1994), esse movimento foi um paliativo para os desamparados, esquecidos e abandonados pela sociedade. A grande maioria deles provinha de famílias de pequenos agricultores que mal conseguiam plantar e sobreviver, devido ao terreno acidentado em que eram assentados.

\subsection{Penso, logo resisto}

Numa sociedade assim construída, a tensão social é rotineira, e diversas rebeliões ocorreram nas ilhas do Caribe. Chevannes (1994) resume a antropologia caribenha a um povo que reage à conquista, resiste à escravidão e às sociedades de plantio impostas pelos conquistadores.

A fim de compreender melhor o objeto de estudo, faz-se necessário um conhecimento mais aprofundado do grupo em que o dialeto foi criado. Partindo das afirmações do filósofo e pensador russo Bakhtin (2006), de que a linguagem é social antes de ser individual, retomaremos algumas questões a respeito da sociedade falante do dialeto. Para entender a motivação ideológica que levou à criação do dialeto, o estudo se fundamenta na sociolinguística, buscando a causa de suas variações, e depois foca as mudanças em si. O sociolinguista estadunidense William Labov (2010) afirma que o coração do estudo sociolinguístico está nas causas da mudança e que não há universais da mudança, mas talvez universais específicos de cada caso. Portanto, deve-se explorar profundamente o caso para buscar seus possíveis universais específicos. 
Para encontrar seu lugar na sociedade, os rastas, como são chamados os adeptos do movimento, precisavam levantar suas bandeiras. A tradição do movimento rastafári tem, de acordo com Campbell (1985) - acadêmico e ativista jamaicano -, fortes ligações com as comunidades maroons de que falamos antes, com as revoltas dos escravos nos séculos 18 e 19 e com a ideologia de Garvey (pan-africanismo ${ }^{2}$, retorno à África, nacionalismo negro) no século 20. Chevannes (1994) corrobora esse argumento, mas salienta o viés social, econômico e cultural do movimento. Os rastas têm plena noção, segundo o autor, da exploração que sofrem pela Igreja e pelo Estado. A bandeira da resistência é então firmada, e os mecanismos utilizados para esse fim vão surgindo.

Edmonds (2003) vê o movimento rastafári como um grupo complexo sem estrutura hierárquica formal, mas com bastante unidade e identidade entre si. Pollard (1984) acrescenta que existem muitos rastas que edificam sua ideologia individualmente, através de uma identificação com a ideologia do movimento. Apesar de existirem grupos formais, como o Rastafarian Theocratic Government (Governo Teocrático Rastafári) ou a Rastafarian Movement Association (Associação do Movimento Rastafári), as produções e criações do movimento partem, muitas vezes, do individual. Yawney (1978) complementa ao afirmar que o movimento rastafári diz respeito a grupos dispersos interligados por redes sociais pessoais, que se encarregariam de unificar mensagens e pensamentos.

A partir do entendimento desses autores, percebemos que houve diversas vertentes ideológicas em diversos locais, convergindo para um sentimento comum: o de que todos eram oprimidos, todos queriam mudanças, todos queriam combater o sistema dominante. A hierarquia viria a se consolidar em pequena escala, dentro de cada casa rastafári, em cada sessão de conversas, como aponta Chevannes (1994).

Existem diversas maneiras de resistir, uma delas é ir contra os padrões estéticos impostos pela classe dominante, padrões de vestimenta, de alimentação etc. Para dar um exemplo bem simples, alguns rastas passaram a cultivar tranças pouco comuns nos cabelos, chamando-as de dreadlocks. Outra forma de resistir é ir contra a norma linguística imposta pelas classes dominantes, adaptando sua linguagem, foco deste artigo.

2 Pan-africanismo, nas palavras de Legum (1965), é um movimento de emoções e ideias. De um lado pode ser comparável ao socialismo, de outro à União Europeia. O autor ainda traça como principal paralelo o sionismo dos judeus, citando DuBois (1919), que afirma que o pan-africanismo é a centralização de esforços raciais e o reconhecimento de uma origem racial. 


\subsection{Dread Talk - A linguagem rastafári}

Nettleford (1970), estudioso e crítico social jamaicano, argumentava, há mais de quatro décadas, que o movimento rastafári, na busca por autoafirmação, vai além da adaptação; segundo ele, trata-se de uma verdadeira criação linguística. Edmonds (2003) concorda com isso e afirma que esse é um artifício utilizado como afronta aos padrões sociais da época: como falar inglês corretamente é o mínimo para ser aceito na sociedade, os rastas decidem desconstruir esse símbolo tão valioso e criar algo diferente a partir disso, algo que represente melhor sua percepção da realidade.

Se pensarmos nas afirmações de Chapman (2006) - a linguagem influencia aquilo que pode ser expresso pelo indivíduo e até mesmo a realidade social depende de sua língua -, vemos que a criação de uma nova língua é um mecanismo de resistência capaz de mudar a própria realidade do grupo social. Segundo o autor, aqueles que falam línguas diferentes vão perceber o mundo de formas diferentes. Criando uma nova língua, o movimento rastafári consegue, além de ver o mundo de outra forma, dar um grande passo na criação de uma identidade própria. Vale lembrar a famosa frase de Wittgenstein, filósofo austríaco, que diz que "os limites da minha linguagem denotam os limites do meu mundo".

Chambers (2009) comenta que, por mais que se escrevam dicionários, livros, gramáticas e afins, os códigos não são eternos. Assim, tanto a linguística conservadora quanto a linguística dominante não são funcionais, existindo como um impulso social. O autor comenta que para erradicá-las não é necessária uma revolução, mas sim educação, incluindo estudos sobre o significado social da variação linguística. E foi essa educação que os rastas passaram a pregar em Kingston, criando uma linguagem muito distinta e inteiramente marcada por valores ideológicos.

Podemos apontar ainda os argumentos de Bourdieu (1991), sociólogo, antropologista e filósofo francês, ainda em 1982, quando diz que a palavra em si não carrega o poder de maneira inerente, mas antes representa o poder atribuído ao interlocutor de um dado discurso, sempre contextualizado em seu uso social. Ou seja, seria uma tarefa difícil, para o movimento que se formava, assumir um discurso crítico à linguagem e à cultura que os dominavam, pois eram aqueles os interlocutores com poder socialmente atribuído. O movimento era marginalizado.

A fim de entender o rastafári, Chevannes (1994) entrevistou diversos membros. Um de seus entrevistados declarou ser um dos criadores do DT, dizendo que fora criado para que ninguém além dos rastas entendesse o que diziam. De acordo com Labov (2010), a habilidade de criar está no indivíduo, mas a mudança 
linguística de fato está na comunidade. Ou então, como coloca Bakhtin (2006), "os signos só podem aparecer em um terreno interindividual", sendo essencial que os indivíduos estejam organizados socialmente para constituir um sistema de signos. Portanto, atribui-se à comunidade em si tal criação.

De acordo com a escritora e professora jamaicana Velma Pollard (2000), a estrutura linguística na Jamaica, tal como se estruturou na década de 60 (e como permanece hoje), é a de um contínuo pós-crioulo. Ao tratar de contínuos linguísticos, deparamo-nos com conceitos como "basileto", "mesoleto" e "acroleto", cunhados por Stewart (1965), mas popularizados por Bickerton (1975). Devemos tomar cuidado ao utilizar esses termos, pois seus significados variam de acordo com o objeto de estudo, conforme aponta Winford (2003). Neste artigo, "basileto" é a variação linguística mais próxima do crioulo jamaicano, enquanto "acroleto" é a variação mais próxima do inglês jamaicano. $\mathrm{O}$ "mesoleto" é uma área de interação entre as duas variações, mas não constitui um sistema linguístico por si só.

Então, dentro do contínuo pós-crioulo jamaicano, o basileto (variação mais informal) é o crioulo jamaicano ou patois (como é chamado pelos nativos), falado pela classe baixa. $\mathrm{O}$ acroleto (variação mais formal) é o inglês jamaicano, falado pelas classes média e alta. Pollard (2000) afirma que, na prática, ninguém fala puramente patois, tampouco inglês. O que acontece é uma adaptação contextual nos diferentes níveis do mesoleto nesse contínuo. Para ilustrar tal situação, adapto um exemplo extraído de Adams (1994):

\begin{tabular}{|c|c|}
\hline Classificação & Exemplo \\
\hline basileto & im ai biggis outai whola mi pikny dem \\
\hline mesoleto baixo & im is di biggist outa whole of mi pikny dem \\
\hline mesoleto alto & (H)e is de biggist one out of all mi kids \\
\hline acroleto & He is the biggest one of my kids \\
\hline
\end{tabular}

Tabela 1: Exemplo do contínuo pós-crioulo na Jamaica

Adaptado de Adams, L. Emilie. Understanding jamaican patois: an introduction to afro-jamaican grammar. Kingston: LMH Publishing, 1994.

O DT surge dentro desse contínuo pós-crioulo e, da mesma forma que o falante comum na ilha varia seu discurso de acordo com as situações, assim também o faz o rasta (Pollard, 2000). 


\subsubsection{Rótulo}

Pollard (2000) afirma que o DT não é simplesmente um dialeto do patois jamaicano, pois o DT reflete a resistência dos falantes ante a opressão sofrida e um sentimento de redenção espiritual que os rastas podem obter através da língua.

Considerando dialeto como uma variedade social e geográfica da linguagem, como afirma Trudgill (2004), poderíamos inferir que o Inglês Jamaicano é um dialeto do Inglês Britânico. Numa escala menor, dentro da Jamaica, o Patois Jamaicano seria um dialeto desse Inglês Jamaicano, numa variação muito mais social do que geográfica. Da mesma forma, se considerarmos o DT como um dialeto do Patois Jamaicano, apesar da afirmação supracitada de Pollard (2000), seria ele então um dialeto de um dialeto de um dialeto (Figura 1)?

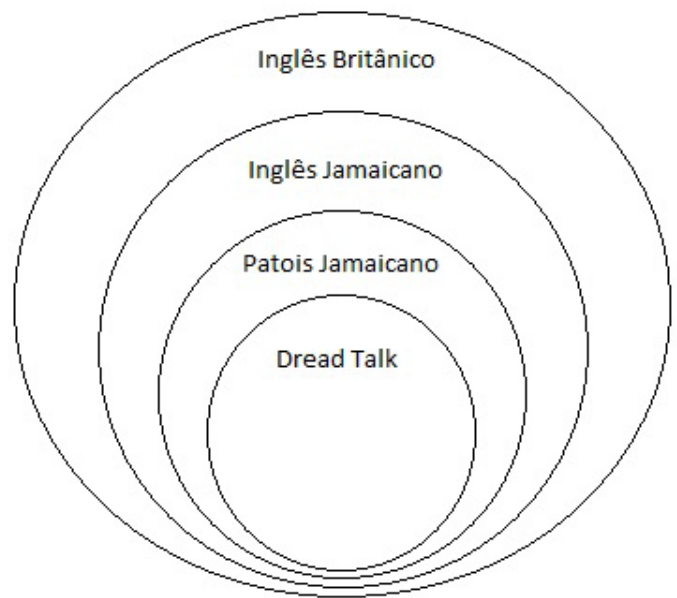

[Figura 1. Luís Labres, Dread Talk como dialeto de um dialeto de um dialeto]

Trudgill (2004) e outros autores (Jean-Baptiste, 1959; Carreira, 2000) dizem que todas as línguas são dialetos e todos dialetos são válidos; não existe o chamado inglês correto, senão para fins teóricos. Para ele, nenhuma dessas variações é linguisticamente superior a outra. O patois jamaicano seria tão funcional quanto o inglês jamaicano ou o britânico, em termos estritamente linguísticos. Também é possível considerar a ideia de um Inglês como Língua Internacional (ILI), sem sotaques específicos, usado para fins didáticos e teóricos, conforme afirmam diversos autores (Pennycook, 1994; Jenkins, 2000; Seidlhofer, 2003), inferindo que todas aquelas variações do inglês seriam dialetos do ILI (Figura 2). 


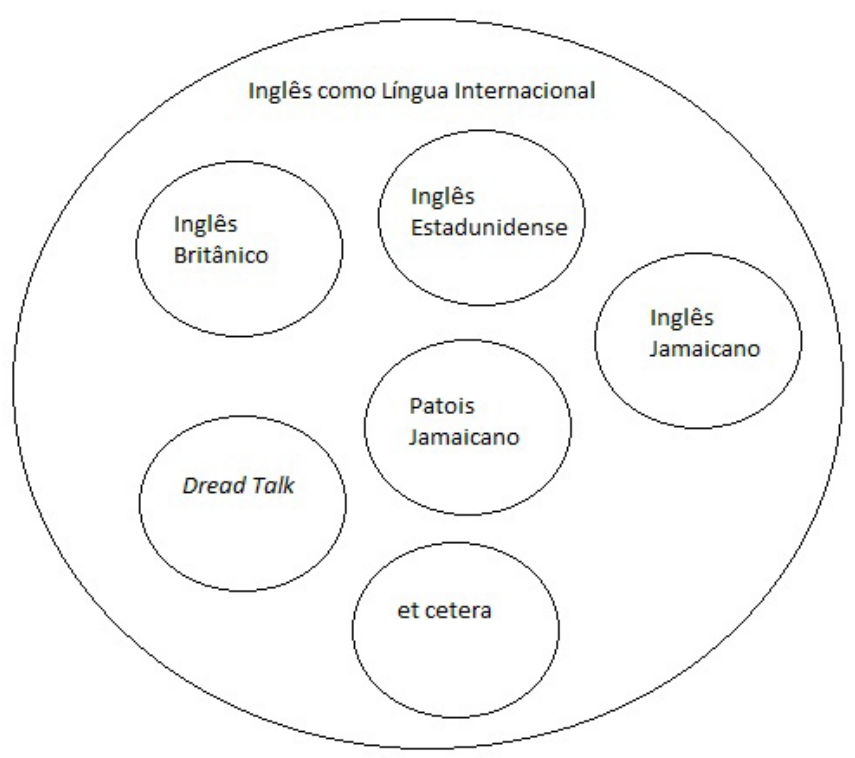

[Figura 2. Luís Labres, Inglês como Língua Internacional e seus dialetos]

Temos ainda a situação linguística idiossincrática da região, conforme explica Pollard (2000): presença de um contínuo pós-crioulo na ilha, convivência de duas línguas e adaptação contextual do interlocutor. Dada a capacidade dos rastas de também adaptar contextualmente o discurso dentro desse contínuo, o DT seria um dialeto do ILI dentro de um contínuo pós-crioulo (Figura 3).

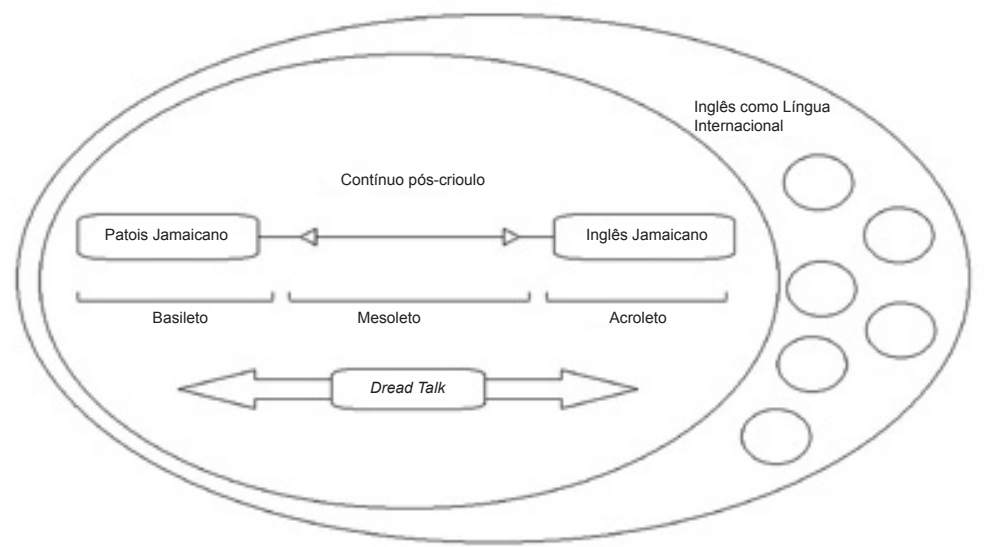

[Figura 3. Luís Labres, Dread Talk como dialeto do ILI dentro de um contínuo pós-crioulo] 


\subsubsection{Essência}

Pollard (2000) explica que as mudanças no DT são basicamente lexicais e fonológicas e classifica as criações lexicais do DT em 4 categorias:

1. Vocábulos existentes no inglês recebem novo significado;

2. Palavras recriadas com base num conceito complexo de "palavra e som";

3. Palavras "I", cuja primeira sílaba é substituída por "I" (pronome de primeira pessoa em inglês);

4. Palavras novas com seus respectivos significados, já existentes ou não.

Vale lembrar ainda que as palavras eram criadas a partir da observação intensa da língua inglesa, como aponta Lee (2003). Após a ideia se espalhar, novas palavras surgiam a cada encontro entre rastas, também como diversão. Abaixo seguem alguns exemplos fornecidos por diferentes autores:

\begin{tabular}{|c|c|c|c|}
\hline Categoria / Autor & Pollard & Mulvaney & Edmonds \\
\hline 1. Novos significados & $\begin{array}{c}\text { Babylon (polícia), } \\
\text { penetrate (buscar a } \\
\text { verdade), red (irritado) }\end{array}$ & $\begin{array}{c}\text { Reason (discutir), trod } \\
\text { (mover-se) }\end{array}$ & \\
\hline $\begin{array}{l}\text { 2. Mudança } \\
\text { Fonológica }\end{array}$ & $\begin{array}{c}\text { Downpress (oprimir), } \\
\text { blainjaret (cigarro) }\end{array}$ & $\begin{array}{l}\text { Overstand (entender), } \\
\text { politricks (política) }\end{array}$ & $\begin{array}{l}\text { Livicate (dedicar), } \\
\text { fullticipate (participar) }\end{array}$ \\
\hline 3. Palavras "I" & $\begin{array}{l}\text { I-ditate (meditar), } \\
\text { I-ration (criação) }\end{array}$ & $\begin{array}{l}\text { I-tal (vital), } \\
\text { Ites (alturas) }\end{array}$ & \\
\hline 4. Palavras novas & $\begin{array}{c}\text { Upful (correto), } \\
\text { satta (relaxe) }\end{array}$ & $\begin{array}{l}\text { Livity (viver uma } \\
\text { vida completa) }\end{array}$ & $\begin{array}{l}\text { Livity (estilo de } \\
\text { vida natural) }\end{array}$ \\
\hline
\end{tabular}

Tabela 2: Exemplos de mudanças lexicais (entre parênteses, significados para os rastas)

Adaptado de Pollard, Velma. Dread Talk: the language of the rastafári. Ed. Rev. Kingston: Canoe Press, 2000; Mulvaney, Rebekah Michele. Rastafari and reggae: a dictionary and sourcebook. New York: Greenwood Press, 1990; Edmonds, Ennis Barrington. Rastafari: from outcasts to culture bearers. New York: Oxford University Press, 2003.

Na primeira categoria, onde palavras existentes ganham novos significados, o significante em si não sofre nenhuma alteração, porém o significado é alterado arbitrariamente. É um caso de neologia semântica, conforme Alves (1994). A categoria apresenta exemplos como baldhead (careca) para designar alguém que não é rasta, Babylon (Babilônia) para se referir à polícia, ou ainda dread (temeroso) para um cumprimento ou para se referir a um rasta. 
A segunda categoria reflete o peso dos sons das palavras. Quando os rastas sentem que alguma palavra não soa como deveria, eles a modificam tentando lhe dar um sentido mais verdadeiro. Um bom exemplo para entender a lógica dessa categoria de palavras é a palavra overstand: surgiu para substituir understand (entender), já que, na lógica rastafári, quando entendemos algo, não ficamos abaixo (under), mas acima (over). Esse é um processo de raiz analógica, semelhante a um dos exemplos de Tagliamonte (2012), mintilicious (mint + delicious). Semelhante porque se trata de uma alteração em nível morfológico, lexical e "talvez semântico", nas palavras dela. Talvez o caso aqui seja mais semelhante ao que Alves (1994) estabelece como recurso fonológico da neologia, numa relação analógica. A autora cita o exemplo do neologismo bebemorar, criado a partir de comemorar e uma relação analógica entre as bases verbais "comer" e "beber". É isso que acontece com os exemplos na segunda categoria exposta por Pollard (2000), com a diferença da motivação ideológica para a mudança.

A terceira talvez seja a mais utilizada pelos rastas. O pronome I (eu) é muito importante para eles. Pollard (2000) aponta que os rastas escolheram o I no lugar do mi (mim) presente no Patois Jamaicano, pois, ao utilizar mi, colocamo-nos como objetos, no lugar do sujeito que somos. Para Chevannes (1994), o uso do I no DT se dá porque o pronome I (eu) é igual ao numeral romano I (um), que segue o nome de Haile Selassie I, imperador da Etiópia, visto pelos rastas como salvador ${ }^{3}$. Mulvaney (1990) concorda com essas duas interpretações, mostrando que não são excludentes.

O pronome I é tão importante que muitas vezes os rastas o utilizam no lugar de todos os pronomes, com algumas variações discutidas mais adiante. Os rastas também colocam o pronome I no começo de diversas palavras, tentando sempre reforçar esse som tão poderoso em sua concepção. Alguns exemplos dessa categoria de palavras são Iditate no lugar de meditate (meditar), e Imen no lugar de Amen (Amém).

A quarta categoria estabelecida por Pollard (2000) é a de palavras novas, inexistentes até então. O melhor exemplo para representar essa categoria é a palavra livity. Edmonds (2003) define essa palavra como um estilo de vida seguindo os padrões rigorosos do rastafári. Mulvaney (1990) aponta ser uma vida em que todos têm o direito de ser completos e felizes. Esse tipo de neologismo é chamado por Alves (2007) de criação ex-nibilo, onde radicais inéditos são utilizados na construção de uma nova palavra.

3 Marcus Garvey, grande ativista pró-negro, teria profetizado a vinda de um rei negro, que seria o salvador de todos; alguns anos depois, Haile Selassie I é coroado imperador da Etiópia, em 1960. 
Como vimos, o movimento rastafári é um sistema complexo, então se espera que haja divergências entre os significados das palavras usadas por cada rasta.

\section{Correlação teórica}

\subsection{Sociolinguística}

Kroch (1978) aponta que grupos sociais dominantes tendem a criar uma simbologia própria distinta dos grupos dominados, interpretando a sua própria criação como superior, moral e intelectualmente. Isso ocorre em diversos aspectos sociais, como vestimentas, alimentação e corte de cabelo, e, além disso, também ocorre na própria linguagem.

O grupo dominante estabelece a norma de uma linguagem supostamente correta, reduzindo formas de comunicação destoantes a uma articulação inferior. Chambers (2009), linguista canadense especialista em variação e mudança, afirma que a causa mais intrínseca das diferenças sociolinguísticas, antes mesmo da consciência, é o instinto humano de estabelecer e manter uma identidade social. O dialeto padrão não é superior em sua função, mas é apresentado como se fosse. Isso nada mais é do que a tentativa de um estrato social de encontrar sua identidade linguística, assim como buscam todos os estratos. Mesmo que a camada mais abastada possua as ferramentas mais poderosas, como, por exemplo, um sistema educacional, a necessidade de identidade de todos os outros estratos não se extingue.

Chevannes (1994) apoia o argumento anterior - de que grupos dominantes buscam a superioridade em diversas esferas - explicando o que é a escravidão ideológica. É aquela que opera através de racismo, menosprezo, criação de estereótipos e com ataques veementes à linguagem do oprimido. Como Chomsky, incansável ativista estadunidense, linguista, crítico social, enfim, comenta em seus estudos, sobre a pejoração atrelada (deliberadamente ou não) a diversas palavras, de maneira que impedem a compreensão do mundo em que vivemos. Apenas para referenciar um dos textos dele que explicam isso, tem uma entrevista de 1988 que está numa compilação publicada em 2004.

Portanto, uma linguagem se torna o padrão devido aos diversos poderes que seu grupo possui: econômicos, políticos, militares e espirituais. Chambers (2009) afirma que os estilos geralmente tidos por superiores tendem a ser imitados; seus costumes, valores, atitudes, roupas, comidas e atividades são aceitos como sendo a norma. A isso se soma o dialeto. Dessa forma, o dialeto almejado pela sociedade é aquele do grupo dominante. 
Bakhtin (2006) argumenta que a própria consciência do indivíduo toma forma com base nos signos criados por um grupo no decorrer de sua história social. Essa consciência cresce de acordo com os signos, refletindo sua lógica e leis. E as consequências residuais da castração ideológica que ocorrera com aqueles que viriam a formar o movimento rastafári perduram até hoje. Essas forças linguísticas antissociais, exemplifica Chambers (2009), acontecem no subconsciente, como a mãe que isola o filho para evitar que ele adquira uma linguagem inadequada na visão dela, ou o supervisor que ignora a sugestão de um funcionário só pela maneira como foi verbalizada.

Em suma,

"(...) a subjugação dos africanos pela força foi acompanhada pela tentativa de introduzir neles, tanto física, psicológica quanto culturalmente, um senso de inferioridade inerente a eles, (...) mas concluir que os subjugadores obtiveram sucesso é o mesmo que confundir a batalha com a guerra. (...) eles resistiram da mesma forma, força contra força, ideias contra ideias." (tradução do autor)

(CHEVANNES, 1994)

E é essa evolução ideológica, conforme Bakhtin (2006), que vai levar à evolução da consciência individual. Ideologia que é expressa através de signos, linguísticos ou não, admitindo-se que a ideologia é externa ao sujeito, já que precisa de signos para existir. $\mathrm{O}$ autor ainda aponta a evolução da língua como principal fator na evolução da consciência individual, através da mudança de estruturas gramaticais e ideológicas.

\subsection{Estudos da tradução}

Cabe pensar, antes de tudo, no que Pym (1992) afirma sobre traduções interculturais. Segundo esse autor, é muito difícil traduzir um texto carregado de variáveis culturais por três motivos: a) é difícil para o tradutor descobrir como os grupos sociais entendem e aceitam as palavras e estilos da variante; b) a chance é muito alta de não existir uma comunidade similar na língua alvo e; c) é difícil julgar como a comunidade da língua alvo vai reagir aos equivalentes criados.

Para entender o que são variáveis culturais, podemos observar o termo culturema (Oksaar, 1988; Vermeer e Witte, 1990; Lungu-Badea, 2004). Nadal (2009) explica que culturema são noções culturais específicas em um país ou em um âm- 
bito cultural, que possuem uma estrutura semântica complexa. Seriam fenômenos sociais de uma cultura $\mathrm{X}$ que, quando comparados a fenômenos semelhantes de uma cultura Y, revelam suas idiossincrasias. O DT é um fenômeno único, com criações únicas, exclusivas da cultura rastafári, e, portanto, essas criações podem ser consideradas culturemas. Dada essa exclusividade cultural, fica mais fácil entender as dificuldades colocadas por Pym (1992).

No entanto, a dificuldade de produzir uma tradução condizente com esses moldes mais motiva do que desanima. Como disse Rónai (1981), "quanto maior a dificuldade, tanto maior o estímulo e maior a satisfação pelo obstáculo superado". A tentativa de tradução de uma linguagem assim nunca deve ser um ato impositivo, mas meramente propositivo. Além disso, não deve, de forma alguma, ser uma tentativa de apropriação, mas pelo contrário, como colocado por Goethe (apud Rónai 1981), ser uma tentativa de apresentar uma beldade velada como altamente digna de amor, excitando uma curiosidade irresistível para conhecermos o original.

A metodologia sugerida segue mais ou menos a dos poetas concretistas aqui no Brasil. Os concretistas respeitavam os conteúdos literais do original, porém se mantinham abertos às novidades da recriação, ou transcriação como costumavam chamar, segundo Jackson (2010). A atenção ao som das palavras também era constante, como fala Augusto de Campos em uma entrevista transcrita: "é uma questão de ouvido". O autor comenta ainda que a tradução que propõem consiste em substituição, reescrita, recriação e espelhamento comparativo, tudo embasado em análises linguísticas.

\section{Fim, ou apenas um começo}

Após a leitura deste trabalho, percebe-se que esse tipo de tradução não se trata de uma tarefa simples. Transportar os elementos socioculturais de um dialeto como esses para outra língua pode beirar o impossível, se queremos evitar uma miríade de notas de rodapé. De fato, o resultado dificilmente parecerá natural o suficiente. Por outro lado, ao não tentar fazê-lo - e traduzir apenas a mensagem -, tornamo-nos responsáveis pela perda de grande parte do contexto sociocultural implícito no objeto da tradução. Afinal, a mensagem quase nunca é puramente textual.

Ao propor um caminho de tradução para o dread talk, espero abrir caminhos para que outros textos escritos nesse dialeto possam ser transpostos para o português: poesias, como "Mabrak" de Bongo Jerry; letras de música, como as citadas neste trabalho; e outros textos que venham a aparecer. Admito que a 
composição textual desse grupo social não é vasta, mas o tipo de análise sugerida para traduzir esses textos pode servir de modelo para outros dialetos semelhantes. Semelhança no quesito "forte presença de elementos socioculturais", na existência de neologismos arbitrários e na própria dificuldade de compreensão. Exemplos de outros dialetos assim são encontrados no Harlem (Jive), em El Paso (Pachuco) e em Londres (Cockney), sendo que diferem bastante entre si, exigindo análises profundamente distintas em cada caso.

Diminuir as distâncias entre culturas pode ser mutuamente benéfico, pois fortalece a cultura dos falantes da língua fonte e amplia o imaginário dos falantes da língua alvo. Estreitar essas relações com a maior naturalidade possível é um dos grandes desafios da tradução, e também uma das grandes contribuições dela para o mundo.

Encerro ainda com dois pensamentos atemporais, um da grande ativista e tradutora estadunidense Maria Tymozcko e outro do poeta e tradutor indiano Attipate Ramanujan:

"O aspecto ideológico da tradução é elevado, pois os tradutores fazem escolhas sobre valores e instituições que vão apoiar ou rejeitar, determinando estratégias de ativismo e escolhendo suas lutas, mesmo quando fazem escolhas sobre o que vai ser levado de um texto fonte ao texto alvo."

(tradução do autor) (TYMOZCKO, 2010)

"Ele [o tradutor] deve deixar a poesia prevalecer, sem deixar de lado a erudição" (tradução do autor) (RAMANUJAN, 1985)

\section{Referências bibliográficas}

ADAMS, L. Emilie. Understanding jamaican patois: an introduction to afro-jamaican grammar. Kingston: LMH Publishing, 1994.

ALVES, Ieda Maria. Neologismo: criação lexical. 2. ed. São Paulo: Ática, 1994.

. Neologia e niveis de análise linguistica. In: As Ciências Do Léxico: Lexicologia, Lexicografia, Terminologia, Vol. 3, pp. 77-91. Campo Grande: Editora UFMS, 2007.

BAKHTIN, Mikhail. Marxismo e filosofia da linguagem. 12a ed. São Paulo: Hucitec, 2006.

BICKERTON, Derek. Dynamics of a creole system. Cambridge: Cambridge University Press, 1975.

BOURDIEU, Pierre. Language and Symbolic Power. Cambridge: Harvard University Press, 1991. 
CAMPBEL, Horace. Rastafari and resistance: from Marcus Garvey to Walter Rodney. London: Hansib Publishing Ltd., 1985.

CARREIRA, Maria. Validating andpromoting spanish in the United States: Lessons from linguistic science. In: Bilingual Research Journal: The journal of the national association for bilingual education. Vol. 24, n. 4. Special Issue: Heritage Language Instruction in the United States. pp. 423-442. Routledge, 2000.

CHAMBERS, J. K. Sociolinguistic theory: linguistic variation and its social significance. Chichester: Wiley-Blackwell, 2009.

CHAPMAN, S. Thinking about language: theories of English. New York: Palgrave Macmillan, 2006.

CHEVANNES, Barry. Rastafari: roots and ideology. Syracuse: Syracuse Univeristy Press, 1994.

CHOMSKY, Noam. Linguistics and Politics. Oakland: AK Press, 2004.

EDMONDS, Ennis Barrington. Rastafari: from outcasts to culture bearers. New York: Oxford University Press, 2003.

JACKSON, David. Transcriação/transcreation: the Brazilian concrete poets and translation. In: TONKIN, Humphrey; FRANK, Maria Esposito. The translator as mediator of cultures. Amsterdam: John Benjamins Publishing Company, 2010. pp. 139-160.

JEAN-BAPTISTE, Alfred. Caribbean english and the literacy tutor: a manual. Toronto: The Toronto ALFA Center, 1959.

JENKINS, Jennifer. Phonology of english as an international language: new models, new norms, new goals. New York: Oxford University Press, 2000.

KROCH, A. Toward a theory of social dialect variation. In: Language in society 7: 17-36, 1978.

LABOV, William. Principles of linguistic change volume 3: cognitive and cultural factors. Chichester: Wiley-Blackwell, 2010.

LALLA, Barbara; D'COSTA, Jean. Language in exile: three hundred years of Jamaican creole. Tuscaloosa: The University of Alabama Press, 1990.

LEE, Hélène. First rasta: Leonard Howell and the rise of rastafarianism. Traduzido por: Lily Davis. Chicago: Chicago Review Press, 2003.

LEGUM, Colin. Pan-africanism: a short political guide. Edição revisada. New York: Frederick A. Praeger, 1965.

LUNGU-BADEA, Georgiana. Teoria culturemelor, teoria traducerii. Timişoara: Editura Universității de Vest, 2004.

MULVANEY, Rebekah Michele. Rastafari and reggae: a dictionary and sourcebook. New York: Greenwood Press, 1990.

NADAL, Lucía Luque. Los culturemas ¿ُunidades lingüísticas, ideológicas o culturales? In: Language Design: Journal of Theoretical and Experimental Linguistics, n. 11, 2009, pp. 93-120. 
NETTLEFORD, Rex M. Mirror, mirror identity, race and protest in Jamaica. Kingston: Collins and Sangster, 1970.

OKSAAR, Els. Kulturentheorie. Hamburg: Vandenhoeck \& Ruprecht, 1988.

PENNYCOOK, Alaistair. The cultural politics of english as an international language: book review. In: Teacher Talking to Teacher. Vol. III, n. 3, Oct. 1995, (pp. 21-23). Harlow: Longman Group Limited, 1994.

POLLARD, Velma. Dread Talk: the language of the rastafári. Ed. Rev. Kingston: Canoe Press, 2000.

. The social history of dread talk. In: Caribbean quarterly. Vol. 28, n. 2. Special issue language, 1984.

PYM, Anthony. Translation and text transfer: an essay on the principles of intercultural communication. Frankfurt: Peter Lang, 1992.

RAMANUJAN, A. K. Poems of love and war: from the eight anthologies and the ten long poems of classical tamil. New York: Columbia University Press, 1985.

RÓNAI, Paulo. A tradução vivida. $2^{\mathrm{a}}$ ed. Rio de Janeiro: Editora Nova Fronteira 1981.

SEIDLHOFER, Barbara. A concept of international English and related issues: from 'real english' to 'realistic english'? Strasbourg: Council of Europe, 2003.

STEWART, William. (1965) Urban negro speech: sociolinguistic factors affecting English teaching. In: SHUY, Roger W. (Ed). Social dialects and language learning. Champaign, Illinois: National Council of Teachers of English. pp. 10-18, 1965.

TAGLIAMONTE, Sali A. Varionist sociolinguistics: change, observation, interpretation. Chichester: Wiley-Blackwell, 2012.

TRUDGILL, Peter. Dialects language workbooks. $2^{\mathrm{a}}$ ed. Oxford: Taylor \& Francis Routledge, 2004.

TYMOCZKO, M. Translation, resistance, activism: an overview. In: TYMOCZKO, M. Translation, resistance, activism. University of Massachusetts Press, 2010. pp. 1-22.

VERMEER, Hans J.; WIT'TE, Heidrun. Mögen sie Zistrosen? Scenes \& frames \& channels im translatorischen Handeln. Heidelberg: Groos, 1990.

WINFORD, Donald. Re-examining caribbean english creole continua. In: World Englishes. Vol. 16, n. 2, pp. 233-279, 1997.

YAWNEY, Carole D. Lions in babylon: the rastafarians of Jamaica as a visionary movement. Thesis dissertation, McGill University, Ottawa, 1978. 